\title{
Anaemia, lead poisoning and vitamin D deficiency in low-income children: do current screening recommendations match the burden of illness?
}

\author{
Margaret Kersey ${ }^{1, *}$, Ming Chi ${ }^{2}$ and Diana B Cutts ${ }^{1}$ \\ 'Department of Pediatrics, University of Minnesota, Hennepin County Medical Center, G7, 701 Park Avenue \\ South, Minneapolis, MN 55415, USA: ${ }^{2}$ Internal Medicine Residency, Saint Joseph's Hospital, Chicago, IL, USA
}

Submitted 26 May 2010: Accepted 22 November 2010: First published online 10 February 2011

\begin{abstract}
Objective: Low-income children are routinely screened for anaemia and elevated blood lead levels (EBLL) but not for vitamin D deficiency. We sought to determine the relative prevalence of and the relationship among vitamin D deficiency, anaemia and EBLL among healthy low-income paediatric clinic patients.

Design: Retrospective chart review.

Setting: Paediatric outpatient clinic in an urban safety net hospital in a northern US state.

Subjects: Healthy toddlers and children under 6 years of age ( $n$ 127) who were seen for a routine well child check-up (WCC).

Results: The prevalence of vitamin D insufficiency (25-hydroxyvitamin D $(25(\mathrm{OH}) \mathrm{D})<30 \mathrm{ng} / \mathrm{ml})$ was $62 \%$; the prevalence of vitamin D deficiency $(25(\mathrm{OH}) \mathrm{D}<20 \mathrm{ng} / \mathrm{ml})$ was $29 \%$. These rates were far higher than those for anaemia $(\mathrm{Hb}<11.0 \mathrm{~g} / \mathrm{dl})$ at $10 \%$, EBLL $(\mathrm{Pb}>9 \mu \mathrm{g} / \mathrm{dl})$ at $1 \%$ or even mildly EBLL ( $\mathrm{Pb} 5-9 \mu \mathrm{g} / \mathrm{dl}$ ) at $4 \%$ (range: $1-11$ ). There was no relationship among any of the following: vitamin D status, anaemia or EBLL. The vast majority of children with vitamin $\mathrm{D}$ deficiency had both normal $\mathrm{Hb}$ (86\%) and $\mathrm{Pb}$ level (100\%). After controlling for child's age, gender and race/ethnicity, there was no association between $\mathrm{Hb}$ (continuous, $\mathrm{g} / \mathrm{dl}$ ) and vitamin $\mathrm{D}$ deficiency (adjusted OR $(\mathrm{aOR})=0.97,95 \%$ CI $0.64,1.47 ; P=0.88)$. The only significant predictor of vitamin D deficiency was increasing age in years $(\mathrm{aOR}=1 \cdot 39,95 \% \mathrm{CI} 1 \cdot 03,1 \cdot 86$; $P=0 \cdot 03$ ). None of these associations changed materially when deficiency was defined as $<15 \mathrm{ng} / \mathrm{ml}$.

Conclusions: Vitamin D deficiency was far more common than anaemia or EBLL, and $\mathrm{Hb}$ and $\mathrm{Pb}$ status were not predictors of vitamin $\mathrm{D}$ status.
\end{abstract}

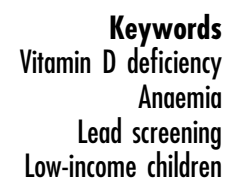

Considerable resources have been devoted to screening for anaemia and elevated blood lead levels (EBLL) among young low-income children. Despite increasing evidence that vitamin D deficiency may have serious adverse health effects and that many children in the USA are at risk of vitamin D deficiency $^{(1-4)}$, no universal or even risk-based vitamin D screening recommendations have emerged to date.

We sought to determine the relative prevalence of and the relationship among vitamin D deficiency, anaemia and EBLL among healthy children in a low-income urban paediatric clinic population in a northern US state. Only one published study to date has examined the relationship between vitamin D deficiency and anaemia ${ }^{(5)}$, and found a positive association between the two in adults. To our knowledge, this has not yet been studied in children.

\section{Experimental methods}

\section{Study participants}

A total of 127 children between the ages of 9 months and 5 years meeting study eligibility criteria with 25-hydroxyvitamin D (25(OH)D) levels measured at the Hennepin County Medical Center (HCMC) Pediatric Outpatient Clinic were assessed in the present study. HCMC is a safety net hospital in Minneapolis, MN (latitude $45^{\circ} \mathrm{N}$ ), serving a lowincome, urban, mostly non-white, largely immigrant (Latin American and East African) patient population. In all, $94 \%$ of our paediatric clinic patients were either publicly insured (88\%) or uninsured (6\%) in 2009.

Partly because of reports of a high prevalence of vitamin D deficiency among adults at our institution, and other studies documenting a very high prevalence of 
vitamin D deficiency among darker-skinned immigrants to northern latitude countries ${ }^{(6-8)}$ and also among breastfed infants in a neighbouring state ${ }^{(4)}$, several paediatric practitioners began measuring $25(\mathrm{OH}) \mathrm{D}$ levels in asymptomatic patients. Paediatric patients considered to be at increased risk of vitamin D deficiency because of increased skin pigmentation and/or possible inadequate dietary intake assessed on the basis of diet history were screened by their paediatricians. Thus, the sample represents a subset of our clinic patients thought to be at higher risk.

A total of 253 children between the ages of 9 months and 5 years had a $25(\mathrm{OH}) \mathrm{D}$ level measured between May 2008 and June 2009. Because we were interested in healthy, asymptomatic children for this retrospective chart review, we restricted our analysis to those with a 25(OH)D level measured along with $\mathrm{Hb}$ and $\mathrm{Pb}$ at well child check-ups (WCC). Our standard practice is to measure both $\mathrm{Hb}$ and $\mathrm{Pb}$ levels at both 1- and 2-year WCC and at least one time thereafter for new patients with unknown levels up to the age of 5 years as per Medicaid (known in our state as MinnesotaCare) guidelines ${ }^{(9)}$. Hb and $\mathrm{Pb}$ levels are occasionally measured at the 9-month rather than the 1-year WCC on the basis of clinical suspicion of increased $\mathrm{Pb}$ or nutritional risk.

The sample was further restricted by excluding those with chronic illness likely to interfere with vitamin D intake or metabolism, or any other physical findings consistent with vitamin D deficiency, including growth failure $(<5 \%$ weight-for-age), gross motor delay or genu varus. Children with any chronic nutritional or neurological condition likely to interfere with nutritional intake or absorption were excluded, as were any with haemoglobinopathies. A three-physician panel of general paediatricians (M.K., D.B.C. and M.H.) blinded to the potential participant's vitamin D status reviewed all cases in which there was any question about study eligibility. Children were deemed eligible if a majority (two out of three) of clinicians believed that a child's underlying medical condition or diagnosis was unlikely to be related to their vitamin D status.

The Institutional Review Board of the Human Subjects Research Committee at HCMC approved the protocol for this anonymous retrospective chart review since no protected health information, or potentially identifiable patient information, was collected.

\section{Laboratory measurements}

$25(\mathrm{OH}) \mathrm{D}(\mathrm{ng} / \mathrm{ml}), \mathrm{Hb}(\mathrm{g} / \mathrm{dl})$ and $\mathrm{Pb}(\mu \mathrm{g} / \mathrm{dl})$ levels were measured in our hospital clinical laboratory. 25(OH)D concentration was measured using RIA (DiaSorin, Stillwater, MN, USA). Because our laboratory does not report Pb levels below $2 \mu \mathrm{g} / \mathrm{dl}$, any measured level below $2 \mu \mathrm{g} / \mathrm{dl}$ was recoded as $2 \mu \mathrm{g} / \mathrm{dl}$. Thus, our estimates of $\mathrm{Pb}$ level overestimate the true values at the very lowest levels.

\section{Definitions}

The measurement and definition of vitamin D deficiency and its functional outcomes in children are hotly debated topics $^{(10,11)}$, and no consensus exists. For this analysis, vitamin D deficiency was defined as serum 25(OH)D $<20 \mathrm{mg} / \mathrm{ml}^{(12-15)}$; vitamin D insufficiency was defined as serum $25(\mathrm{OH}) \mathrm{D}<30 \mathrm{ng} / \mathrm{ml}^{(11,15,16)}$. The more restrictive definition of deficiency as $25(\mathrm{OH}) \mathrm{D}<15 \mathrm{ng} / \mathrm{ml}$ as has been used by others ${ }^{(1)}$ was also utilized.

Anaemia was defined using WHO criteria as $\mathrm{Hb}$ $<11.0 \mathrm{~g} / \mathrm{dl}$ for ages $0.5-4.99$ years and $<11.5 \mathrm{~g} / \mathrm{dl}$ for ages $5-11.99$ years $^{(17)}$.

EBLL was defined using the definition of the Centers for Disease Control and Prevention (CDC) $\geq 10 \mu \mathrm{g} / \mathrm{dl} \mathrm{Pb}$. However, on the basis of evidence of $\mathrm{Pb}$ neurotoxicity even at levels $<10 \mu \mathrm{g} / \mathrm{dl}^{(18,19)}$, we created a category that we called 'mildly EBLL', defined as $\mathrm{Pb}$ level $\geq 5 \mu \mathrm{g} / \mathrm{dl}$ but $<10 \mu \mathrm{g} / \mathrm{dl}$, based on the threshold reported by Jusko et $a l^{(18)}$ as a more sensitive measure of elevated risk.

\section{Clinical and antbropometric data}

Clinical data, including the patient's problem list and past medical history, diagnosis at current visit, height, weight and BMI percentile (BMI\%ile) data, were extracted by chart review of the well child notes from our electronic health record (EHR). Race/ethnicity data were extracted from the demographics section of the EHR, which is originally determined by parental report, although we were unable to determine country of birth. We were also unable to extract usable data on vitamin D intake from the WCC notes since providers generally documented the type of milk (breast, formula, soya or cow's milk) consumed but not the volume, which prevented abstractors from determining whether the dietary intake was adequate. Similarly, although many infants and children had been prescribed a multivitamin, providers were inconsistent about documenting adherence unless there was a significant concern.

\section{Statistical analysis}

Analyses were conducted with the STATA statistical software package version $8 \cdot 0$ (StataCorp, College Station, TX, USA). Bivariate statistics were determined using $\chi^{2}$ tests for categorical data, $t$ tests for continuous variables with normal distributions and Pearson's product-moment correlations for pairwise correlations.

Multivariate logistic regression models were constructed with vitamin D status ('deficient' $v$. 'not deficient') as the outcome variable, $\mathrm{Hb}$ as the independent variable and relevant patient demographics and health status variables included as covariates. Both $\mathrm{Hb}$ and several of the demographic covariates were modelled in several different ways (i.e. $\mathrm{Hb}$ as both a continuous and categorical variable; age as continuous, multiple categorical and dummy variables). We were unable to include $\mathrm{Pb}$ as a predictor variable because of the narrow range of values 
found for serum $\mathrm{Pb}$. Potentially confounding variables were assessed by serially adding and removing each variable to assess its effect on the point estimates and statistical significance of the remaining variables in the model. The final model was chosen on the basis of its parsimony and ease of interpretation (e.g. with $\mathrm{Hb}$ modelled as a continuous variable); its results did not differ materially from those of alternative models. 25(OH)D was also modelled as a continuous outcome for multivariate linear regression. For all analyses, $P<0.05$ was considered statistically significant.

\section{Results}

The final sample consisted of 127 children (Table 1). The prevalence of vitamin D insufficiency $(25(\mathrm{OH}) \mathrm{D}$ $<30 \mathrm{ng} / \mathrm{ml}$ ) was $62 \%$; the prevalence of vitamin D deficiency $(25(\mathrm{OH}) \mathrm{D}<20 \mathrm{ng} / \mathrm{ml})$ was $29 \%$. These rates were far higher than those for anaemia $(\mathrm{Hb}<11.0 \mathrm{~g} / \mathrm{dl})$ at $10 \%$, EBLL $(\mathrm{Pb}>9 \mu \mathrm{g} / \mathrm{dl})$ at $1 \%$ (one child, with a level of $11 \mu \mathrm{g} / \mathrm{dl}$ ) or even mildly EBLL (level 5-9 $\mu \mathrm{g} / \mathrm{dl}$ ) at $4 \%$.

We were unable to measure the effect of season of the year since our practitioners did not begin measuring vitamin D 25(OH)D levels in earnest until the winter of 2009, and the chart review was completed on 1 June 2009. Thus, $93 \%$ of sampling occurred during the winter and spring months. In addition, although others have documented a higher risk of vitamin D deficiency among overweight patients, we did not measure the effect of

Table 1 Characteristics of the study population: low-income children under 6 years of age ( $n$ 127), Minnesota, USA

\begin{tabular}{lccc}
\hline Characteristic & $n$ or Mean & \% or SD & Range \\
\hline Gender & & & \\
Female & 64 & 50 & \\
Male & 63 & 50 & \\
Age (years) & $2 \cdot 6$ & $1 \cdot 5$ & $0 \cdot 8-5 \cdot 7$ \\
Race/ethnicity & 6 & 5 & \\
Non-Hispanic white & 53 & 42 & \\
Non-Hispanic black & 42 & 33 & \\
Hispanic/Latino & 15 & 12 & \\
Somali American & 11 & 9 & \\
Other & $26 \cdot 8$ & $11 \cdot 5$ & $4 \cdot 9-58 \cdot 2$ \\
25(OH)D level (ng/ml) & 79 & 62 & \\
Insufficient $(<30)$ & 37 & 29 & \\
Deficient $(<20)$ & 17 & 13 & \\
Deficient $(<15)$ & $12 \cdot 1$ & $1 \cdot 0$ & $8 \cdot 4-15 \cdot 9$ \\
Hb (g/dl)* & 13 & 10 & \\
Anaemic $(<11 \cdot 0)$ & $2 \cdot 0$ & & $2-11$ \\
Pb ( $\mu$ g/dl) $\dagger$ & 1 & 1 & \\
EBLL $(>9)$ & 5 & 4 & \\
Mildly EBLL (5-9) & & & \\
Season of blood sampling & 43 & 34 & \\
Winter & 75 & 59 & \\
Spring & 1 & 1 & \\
Summer & 8 & 6 & \\
Fall & & &
\end{tabular}

25(OH)D, 25-hydroxyvitamin D; EBLL, elevated blood lead levels. ${ }^{*}$ Data are mean, SD and range.

tLead reported as median rather than mean because of right skew; values $<2$ are collapsed and thus reported as 2 for analysis. weight status on vitamin D status, since age- and sexspecific BMI\%ile data were available only for children aged $\geq 3$ years, who comprised $<50 \%$ of our sample (forty-six out of 127).

There was no statistically significant relationship among any of the following outcomes: vitamin D status, anaemia or EBLL (Figs 1 and 2). Bivariate associations are shown in Table 2. Furthermore, the vast majority of children with vitamin $\mathrm{D}$ deficiency had both a normal $\mathrm{Hb}$ level $(32 / 37$ or $86 \%)$ and a normal $\mathrm{Pb}$ level $(37 / 37$ or $100 \%$ ). Although elevated blood $\mathrm{Pb}$ can suppress $\mathrm{Hb}$ production and is thus an important risk factor for anaemia, this possible interaction was not tested in our sample since, according to $\mathrm{CDC}$, blood $\mathrm{Pb}$ does not begin to suppress $\mathrm{Hb}$ until it reaches $25-40 \mu \mathrm{g} / \mathrm{dl}^{(16)}$, which is far higher than even the highest blood $\mathrm{Pb}$ levels seen in our sample.

After controlling for child's age, gender and race/ethnicity, there was no association between $\mathrm{Hb}$ (continuous, g/dl) and vitamin D deficiency (adjusted OR (aOR) $=0 \cdot 97 ; 95 \%$ CI $0 \cdot 64,1 \cdot 47 ; P=0 \cdot 88$; Table 3 ). The only significant

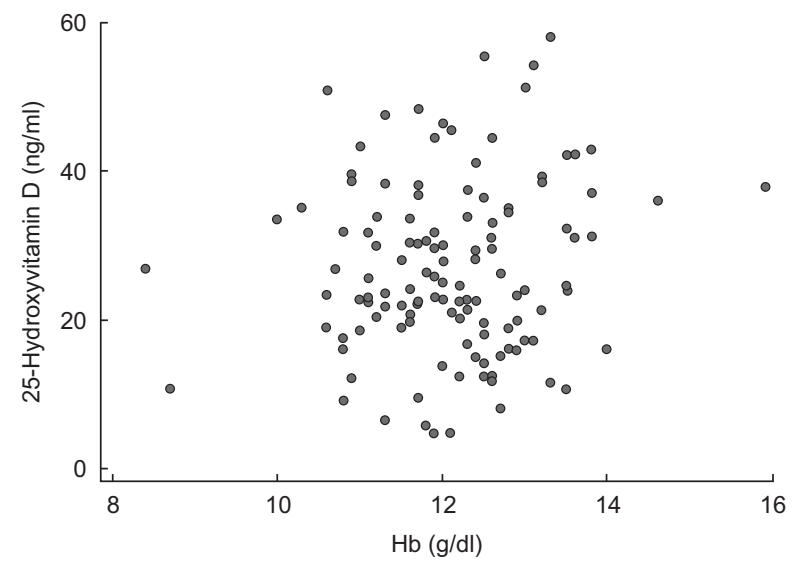

Fig. 1 Two-way scatterplot of vitamin $\mathrm{D}$ status and $\mathrm{Hb}$ level ( $n$ 127; $r=0.12 ; P=0.18$ ) among low-income children under 6 years of age ( $n$ 127), Minnesota, USA

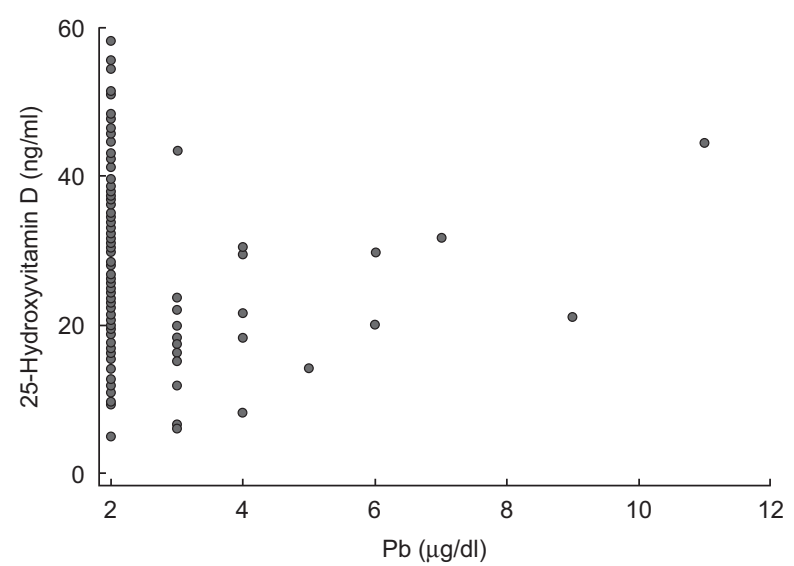

Fig. 2 Two-way scatterplot of vitamin $D$ status and lead level ( $n$ 127; $r=0.03 ; P=0.71$ ) among low-income children under 6 years of age ( $n 127)$, Minnesota, USA 
Table 2 Associations of vitamin D deficiency and insufficiency among low-income children under 6 years of age ( $n$ 127), Minnesota, USA

\begin{tabular}{|c|c|c|c|c|c|c|c|}
\hline \multirow[b]{2}{*}{ Characteristic } & \multirow[b]{2}{*}{ Total } & \multicolumn{2}{|c|}{$\begin{array}{l}\text { Vitamin D deficient } \\
(25(\mathrm{OH}) \mathrm{D}<20 \mathrm{~g} / \mathrm{ml})\end{array}$} & \multirow[b]{2}{*}{$P^{*}$} & \multicolumn{2}{|c|}{$\begin{array}{l}\text { Vitamin D insufficient } \\
(25(\mathrm{OH}) \mathrm{D}<30 \mathrm{~g} / \mathrm{ml})\end{array}$} & \multirow[b]{2}{*}{$P^{*}$} \\
\hline & & $n$ & $\%$ & & $n$ & $\%$ & \\
\hline All & 127 & 37 & 29 & N/A & 79 & 62 & $\mathrm{~N} / \mathrm{A}$ \\
\hline Gender & & & & 0.07 & & & 0.30 \\
\hline Female & 64 & 14 & 22 & & 37 & 58 & \\
\hline Male & 63 & 23 & 37 & & 42 & 67 & \\
\hline Age (months) & & & & 0.07 & & & $<0.01$ \\
\hline $9-24$ & 49 & 12 & 24 & & 22 & 45 & \\
\hline $25-36$ & 50 & 12 & 24 & & 36 & 72 & \\
\hline $37-60$ & 28 & 13 & 46 & & 21 & 75 & \\
\hline Race/ethnicity & & & & 0.39 & & & 0.81 \\
\hline Non-Hispanic white & 6 & 2 & 33 & & 3 & 50 & \\
\hline Non-Hispanic black & 53 & 15 & 28 & & 32 & 60 & \\
\hline Hispanic/Latino & 42 & 16 & 38 & & 29 & 69 & \\
\hline Somali American & 15 & 2 & 13 & & 9 & 60 & \\
\hline Other & 11 & 2 & 18 & & 6 & 55 & \\
\hline Anaemia status & & & & 0.44 & & & 0.96 \\
\hline Anaemic $(\mathrm{Hb}<11 \mathrm{~g} / \mathrm{dl})$ & 13 & 5 & 38 & & 8 & 62 & \\
\hline Non-anaemic & 114 & 32 & 28 & & 71 & 62 & \\
\hline $\mathrm{Pb}$ status $(\mu \mathrm{g} / \mathrm{dl})$ & & & & 0.73 & & & 0.31 \\
\hline EBBL $(>9)$ & 1 & 0 & 0 & & 0 & 0 & \\
\hline Mildly EBBL (5-9) & 5 & 1 & 20 & & 4 & 80 & \\
\hline Normal $(<5)$ & 121 & 36 & 30 & & 75 & 62 & \\
\hline
\end{tabular}

25(OH)D, 25-hydroxyvitamin D; EBLL, elevated blood lead levels.

${ }^{*} P$ values for equal prevalence in all categories determined by the $\chi^{2}$ statistic.

Table 3 Multivariate logistic regression model for vitamin $D$ deficiency $(25(\mathrm{OH}) \mathrm{D}<20 \mathrm{ng} / \mathrm{ml})$ among low-income children under 6 years of age ( $n$ 127), Minnesota, USA

\begin{tabular}{lccc}
\hline & aOR & $95 \% \mathrm{Cl}$ & $P$ \\
\hline Hb, continuous (g/dl) & 0.97 & $0.64,1.47$ & 0.88 \\
Age (years) & $\mathbf{1 . 3 9}$ & $\mathbf{1 . 0 3 , 1 . 8 6}$ & $\mathbf{0 . 0 3}$ \\
Gender, male (ref. = female) & 1.93 & $0.85,4.37$ & 0.12 \\
Race/ethnicity & & & \\
$\quad$ Non-Hispanic white (ref.) & 1.00 & - & - \\
Non-Hispanic black & 0.78 & $0.11,5.30$ & 0.80 \\
Hispanic/Latino & 1.35 & $0.20,9.24$ & 0.76 \\
Somali American & 0.27 & $0.02,2.99$ & 0.27 \\
Other & 0.42 & $0.04,4.70$ & 0.49 \\
\hline
\end{tabular}

25(OH)D, 25-hydroxyvitamin D; aOR, adjusted OR; ref., reference category.

predictor of vitamin $\mathrm{D}$ deficiency was increasing age in years $(\mathrm{aOR}=1 \cdot 39 ; 95 \% \mathrm{CI} 1 \cdot 03,1 \cdot 86 ; P=0 \cdot 03)$. None of these associations changed materially when deficiency was defined more restrictively at $<15 \mathrm{ng} / \mathrm{ml}$.

$25(\mathrm{OH}) \mathrm{D}$ was also modelled as a continuous outcome in multivariate linear regression. Age in years remained inversely associated with $25(\mathrm{OH}) \mathrm{D}$ level, with a $-1.92 \mathrm{ng} / \mathrm{dl}$ change in $25(\mathrm{OH}) \mathrm{D}$ level for each increasing year of age $(95 \% \mathrm{CI}-3 \cdot 34,-0 \cdot 48, P<0 \cdot 01)$. All other predictor variables $(\mathrm{Hb}$, race/ethnicity and gender) remained non-significant $(P>0 \cdot 10)$.

\section{Discussion}

This sample of low-income, at-risk urban young children had much higher rates of vitamin D deficiency than of either anaemia or EBLL, although study generalizability may be limited because of the far northern latitude of our state, the fact that the majority of blood sampling occurred in winter and spring and because of small sample size.

Our sample was likely too small in size and had too high a proportion of darkly pigmented children for variation to be examined by ethnicity. On the basis of the unpublished findings of our adult medicine colleagues, who documented a $94 \%$ prevalence of vitamin D insufficiency in Somali Americans at our institution (D Pryce, personal communication), the prevalence of vitamin D deficiency among Somali-American toddlers in our clinic was much lower than we initially expected. However, we believe that this can be explained largely by our Somali mothers' very low rates of exclusive breast-feeding, as a systematic chart review at our institution found that only $4 \%$ (one of the twenty-six) of Somali mothers were exclusively breast-feeding at postpartum hospital discharge (A Mueller, personal communication). Therefore, most Somali infants in our practice receive at least some vitamin $\mathrm{D}$ in formula. This finding would explain the low rate of deficiency (13\%) but high rate of insufficiency (60\%) among this patient population.

The prevalence of vitamin D deficiency was far higher than for anaemia or $\mathrm{Pb}$ poisoning. It may seem surprising that our rates of vitamin D deficiency and insufficiency were not much higher than national estimates such as those found by Kumar et $a l^{(1)}$, given our far northern latitude, dark-skinned urban patient population and season of the bulk of blood sampling (winter and spring). However, the prevalence of vitamin D deficiency is 
strongly associated with increasing age in childhood ${ }^{(1,20)}$, and our sample was much younger than Kumar's, with a mean age of only 2.6 years compared with a National Health and Nutrition Examination Survey sample uniformly distributed between the ages of 1 and 21 years. Our prevalence was higher than that found in a sample of children of roughly similar age, ethnic background and northern latitude ${ }^{(13)}$.

Two recent articles have been published that document low $(<50 \%)$ rates of vitamin D supplementation among breast-fed infants, even among parents who admit to receiving information from their child's paediatrician about the importance of supplementation ${ }^{(21,22)}$. Thus, although we agree that screening has significant costs (both direct and indirect), a policy of 'universal' supplementation also has significant limitations, as the available evidence suggests that it is likely to result in supplementation far below recommended levels ${ }^{(21,22)}$. We eagerly await evidence-based guidelines on this much debated topic.

\section{Conclusion}

There was no correlation among vitamin D, anaemia and $\mathrm{Pb}$ status in our low-income paediatric population. Further studies that examine the geographical variability and clinical significance of vitamin D deficiency are anticipated. In the interim, our data suggest that new recommendations for vitamin D screening, or universal supplementation, are sorely needed for at-risk children.

\section{Acknowledgements}

The present study did not receive any external funding. The authors have no conflict of interest to declare. M.K. conceived of the study, performed a portion of the data analysis and wrote the paper; M.C. performed a portion of the data analysis and edited the manuscript; D.B.C. collaborated on study conception, data analysis and edited the manuscript.

\section{References}

1. Kumar J, Muntner P, Kaskel FJ et al. (2009) Prevalence and associations of 25-hydroxyvitamin D deficiency in US children: NHANES 2001-2004. Pediatrics 124, e1-e9.

2. Gordon CM, Williams AL, Feldman HA et al. (2008) Treatment of hypovitaminosis D in infants and toddlers. $J$ Clin Endocrinol Metab 93, 2716-2721.

3. Mansbach JM, Ginde AA \& Camargo CA (2009) Serum 25-hydroxyvitamin D levels among US children aged 1 to 11 years: do children need more vitamin D? Pediatrics 124, 1404-1410.
4. Ziegler EE, Hollis BW, Nelson SE et al. (2006) Vitamin D deficiency in breastfed infants in Iowa. Pediatrics 118, 603-610.

5. Sim JJ, Lac PT, Liu IL et al. (2009) Vitamin D deficiency and anemia: a cross-sectional study. Ann Hematol 89, $447-452$.

6. McGillivray G, Skull SA, Davie G et al. (2007) High prevalence of asymptomatic vitamin D and iron deficiency in East African immigrant children and adolescents living in a temperate climate. Arch Dis Child 92, 1088-1093.

7. Madar AA, Stene LC \& Meyer HE (2009) Vitamin D status among immigrant mothers from Pakistan, Turkey and Somalia and their infants attending child health clinics in Norway. Br J Nutr 101, 1052-1058.

8. Hintzpeter B, Scheidt-Nave C, Muller MJ et al. (2008) Higher prevalence of vitamin D deficiency is associated with immigrant background among children and adolescents in Germany. J Nutr 138, 1482-1490.

9. Minnesota Department of Human Services and Health (2006) Child and Teen Checkups (CETC) Screening Components Standards and Guidelines. St Paul, MN: Minnesota Department of Human Services and Health.

10. Greer FR (2009) Defining vitamin D deficiency in children: beyond $25-\mathrm{OH}$ vitamin D serum concentrations. Pediatrics 124, 1471-1473.

11. Holick MF (2009) Vitamin D status: measurement, interpretation, and clinical application. Ann Epidemiol 19, 73-78.

12. Holick MF (2006) High prevalence of vitamin D inadequacy and implications for health. Mayo Clin Proc 81, 353-373.

13. Gordon CM, Feldman HA, Sinclair L et al. (2008) Prevalence of vitamin D deficiency among healthy infants and toddlers. Arch Pediatr Adolesc Med 162, 505-512.

14. Lee JM, Smith JR, Philipp BL et al. (2007) Vitamin D deficiency in a healthy group of mothers and newborn infants. Clin Pediatr (Phila) 46, 42-44.

15. Cole CR, Grant FK, Tangpricha V et al. (2010) 25-Hydroxy vitamin D status of healthy, low-income, minority children in Atlanta, Georgia. Pediatrics 125, 633-639.

16. Agency for Toxic Substances and Disease Registry, Centers for Disease Control and Prevention (2007) Lead toxicity: what are the physiologic effects of lead exposure? http:// www.atsdr.cdc.gov/csem/lead/pbphysiologic_effects2.html (accessed April 2010).

17. McLean E, Cogswell M, Egli I et al. (2009) Worldwide prevalence of anaemia, WHO Vitamin and Mineral Nutrition Information System, 1993-2005. Public Health Nutr 12, 444-454.

18. Jusko TA, Henderson CR, Lanphear BP et al. (2008) Blood lead concentrations $<10 \mu \mathrm{g} / \mathrm{dl}$ and child intelligence at 6 years of age. Environ Health Perspect 116, 243-248.

19. Canfield RL, Henderson CR Jr, Cory-Slechta DA et al. (2003) Intellectual impairment in children with blood lead concentrations below $10 \mu \mathrm{g}$ per deciliter. $N$ Engl J Med $\mathbf{3 4 8}$, $1517-1526$.

20. Yetley EA (2008) Assessing the vitamin D status of the US population. Am J Clin Nutr 88, 558S-564S.

21. de Nooijer J, Onnink M \& Van Assema P (2010) Vitamin D supplementation in young children: associations with Theory of Planned Behavior variables, descriptive norms, moral norms, and habits. Public Health Nutr 13, 1279-1285.

22. Taylor JA, Geyer LJ \& Feldman KW (2010) Use of supplemental vitamin D among infants breastfed for prolonged periods. Pediatrics 125, 105-111. 